Research Paper

\title{
Build IoT through Virtual Reality
}

\author{
Muhammad Azri Ishak ${ }^{1}$, Mohammad Rafiq Kosnan ${ }^{1}$, Nur Fatini Zakaria ${ }^{1}$ \\ ${ }^{1}$ Program of Software Engineering, Department of Computing, Faculty of Arts, \\ Computing, and Industry Creative. Universiti Pendidikan Sultan Idris, Malaysia.
}

\section{Article History}

Received:

07.12.2019

Revised:

17.01.2020

Accepted:

20.02.2020

*Corresponding Author:

Muhammad Azri Ishak

Email:

baie457@gmail.com

This is an open access article, licensed under: $\mathrm{CC}-\mathrm{BY}-\mathrm{SA}$
Abstract: Virtual Reality is a new form as integration of technologies that overlays computer-generated information on real world. Virtual reality can be used to enhance student learning and engagement. VR education can transform the way educational content is delivered; it works on the premise of creating a virtual world, real or imagined and allows users not only see it but also interact with it. Hence, educator has begun to seek technologies that have potential to be integrated in education in order to help students learn effectively and enhance their understanding. The focus of this research is on development of mobile application on Raspberry Pi topic by using Virtual Reality technology from Computer Architecture and Organization subject in Universiti Pendidikan Sultan Idris (UPSI). Student have difficulty to understand and even not know what is Raspberry Pi besides less usage of mobile application on Virtual Reality, the application could help them understand the functionality of Raspberry Pi better and effectively. By using Prototyping Model, evaluation phase consisted of post tested have been carried out on target user as to see the learning effectiveness from student achieved. The result of finding shows that the students think that VR-Pi application is easy to use and the note provided is appropriate and easy to understand. Thus, this mobile application of VR technology could enhance the traditional form of teaching and learning in order to improve student's knowledge and interest about Raspberry Pi which improves their understanding and experience using technology for learning.

Keywords: Computational Thinking, Education Technology, Industrial Revolution 4.0, Internet of Things, Virtual Reality. 


\section{Introduction}

In the globalization of the technology's today, there are variety of the new technology have been developed and implemented based on Virtual Reality. VR is defined as the computer-generated simulation of a three-dimensional image or environment that can be interacted with in a seemingly real or physical way by a person using special electronic equipment, such as a helmet with a screen inside or gloves fitted with sensors [1]. Virtual Reality is leading in providing education to the society. This also giving the opportunity to the society to learn something that is far or extinct. One of the example is learning our solar system that is most people google on it. Not every person able to go to out space by chance to feel the immersive like Virtual Reality able to. Most of big company like Nintendo, Samsung, HTC and Google start to produce Virtual Reality gear. Virtual Reality may give a big impact to the society in the future. Games, movie, education, and many more can be created and be used with Virtual Reality as to attract society to learn something.

Industrial Revolution (IR) is the period of time that involve of major industrialization and innovation that took place during late $1700 \mathrm{~s}$ and early $1800 \mathrm{~s}$. The era of Industrial Revolution began with $1.0 \mathrm{IR}$ that is focusing on iron production, 2.0 IR is focusing on mass production assembly lines with electricity, 3.0 IR is focusing on automated production using electronics and Information Technology (IT), and 4 IR which is present is focusing on digitalization and connection of all factors in the value process. All the revolution has changes our life style and even in our job scope. It is not a new phenomena but continues progress as new technology and science achieved. 4 IR is step in era of innovation and technology like Artificial Intelligence and Robotics. As mention in the Education Minister speech 2018, he advice for 4IR to be widely used and apply in Malaysia. Plus, the Education Minister hope that most of the student will learn and apply as this may be a huge benefits and advantage to the country in the future [2]. Thus, by performing this task of preparing software involving Virtual Reality is indirectly supporting and executing the mandate of education minister who wants 4IR to be implemented in Malaysia.

Raspberry $\mathrm{Pi}$ is one of the educational component that are used in creating many type of things such as Raspberry Pi as video server, people identification and counting system using Raspberry Pi and smart ring for women safety using IoT. To create IoT using Raspberry Pi might be costly, so by giving chance to student to create IoT via Virtual Reality is another way to enhance their skills.

The first main problem faced by student lately in learning is about the concentration during classes. Direct teaching might be boring during class. Sometime students feel no encourage or confident to ask question during lecture. Possibility for student to left behind with the topic that are taught during class is high. Theory that are taught in the classroom also another reason for the student not get a clear picture of certain topic.

Raspberry $\mathrm{Pi}$ is a micro-controller that connected too many component and involve with programming language. Student might find it hard if they want to develop IoT based with Raspberry Pi by only theory. The immersive feeling through the application from Virtual Reality will enhance the student involvement. Plus, student will feel attracted to learn the topic from the environment in the application. This initiative will surely give an advantage to the student to learn new micro-technology in creating things like robotic, controlled car, and many more. The ability of Virtual Reality in educate people is on another level. Student interaction with fully immersive from Virtual Reality will give a good impact in learning [3, 4].

This software will help student to learn basic component in creating Internet of Things (IoT). Virtual Reality also will strike the boundary of limitation in gaining knowledge of creating things with Raspberry Pi. This will give a huge chances for student to learn Raspberry Pi without limitation. Plus, this software will fulfill the Ministry of Education mandate [2].

Student will wear the Virtual Reality gear to start the game. Student gain knowledge from component explanation during game session. Student be able to create one of their favorite idea by using component provided with guide. Incomplete component won't allow user to proceed to next phase which is play with their creation. User will get notify with component missing such as power supply, tyre, shaft and many more.

User can play or demo their creation after all component is fully installed.

1. User - Student that interested in learning Artificial Intelligence and Raspberry Pi

2. Content - The component involve in the making of Raspberry Pi and its function.

3. Platform - Unity 


\section{Literature Review}

This section contains various information and study that concentrates to the proposed project. The information gain from this literature review will be used as a guideline to develop the proposed software based on Virtual Reality.

\subsection{Virtual Reality}

Education as the main priority as world leading forward with technology. Technology in education has seen to increase in availability for the past 5 year. Artificial Intelligence takes place as option for student to gain knowledge in attractive way. Virtual Reality has the potential to offer student a novel way to explore the knowledge. The definition of 'virtual' is near and reality is what we experience as human beings. The term 'virtual reality' basically means 'near-reality' [5].

As we know the world through our senses and perception systems. In school we all learned that we have five senses: taste, touch, smell, sight and hearing. These are however only our most obvious sense organs. The truth is that humans have many more senses than this, such as a sense of balance for example. These other sensory inputs, plus some special processing of sensory information by our brains ensures that we have a rich flow of information from the environment to our minds.

Today virtual reality is usually implemented using computer technology. There are a range of systems that are used for this purpose, such as headsets, omni-directional treadmills and special gloves. These are used to actually stimulate our senses together in order to create the illusion of reality [6].

There are wide variety of applications for Virtual Reality which include architecture, medicine, entertainment, sport and arts. From trainee fighter pilots to medical applications trainee surgeons, virtual reality allows us to take virtual risks in order to gain real world experience. As the cost of virtual reality goes down and it becomes more mainstream you can expect more serious uses.

\subsection{Raspberry Pi}

The Raspberry Pi is credit-card sized computer that plugs into a computer monitor or TV, and uses a standard keyboard and mouse. It is capable little device that enables people of all ages to explore computing, and to learn how to program in languages like Scratch and Python [7, 8]. It's capable of doing everything you'd expect a desktop computer to do, from browsing the internet and playing highdefinition video, to making spreadsheets, word-processing, and playing games.

Raspberry Pi has the ability to interact with the outside world, and has been used in a wide array of digital maker projects, from music machines and parent detectors to weather stations and tweeting birdhouses with infra-red cameras. Promoting Raspberry Pi being used by kids all over the world to learn to program and understand how computer work $[9,10]$.

Raspberry $\mathrm{Pi}$ is one of another things after Arduino in education. Less opportunities for student to learn Raspberry Pi like in rural area. Limitation or boundary in education need to be break. The integration of Raspberry Pi consist of human-oriented vision, internet-oriented vision, sensor and knowledge.

Smart Camera is one of the many example where this thing is implemented. This surveillance camera help to track and display the result of person with accurate data. Displaying person name and also displaying car plate number for transportation. This trace and track also giving accurate reading when on crowded situation. This invention will help a lot to the authorities in managing criminal that occur in their country. This invention also been used by convenient store to verify their registered customer for point collection and discount. Customer also be able to pay by using their phone which is much convenient. Plus, user also can give rating on certain issue which give credit score to company for better changes in future.

Developing on smart building will increase the safety and data information to the user. Such as smart sensor that detect celcius whether air conditioning is turn off or not, then notify to the user via phone notification. This will ensure electrical saving by only using Raspberry Pi as tools in sensing the celcius. Plus, many things can be done by using Raspberry Pi such as emergency smart car for disaster situation like building collapse. Ease of use for user by controlling the things from Raspberry Pi for collecting data and many more. The development of Internet of Things by using Virtual Reality is less. People tend to learn with physical things while there is much of way to learn interactively.

Many component involve before the creation is fully functional. A fully functional connection starting from power supply, internet connection, Ethernet, coding and much more can be done by student as learning part from Raspberry Pi. 


\subsection{Social Virtual Reality Education System for Experiential Learning}

IoT has played a big role in the safety and health for construction workers. Due to high risk of accident that happen in industry, by developing the Virtual Reality of game activity which is inspection game will help student or workers to avoid or overcome dangers from happen. This to ensure the safety of worker is guaranteed. By using Virtual Reality as the platform to introduce to the accident that might happen for a certain situation. Some of the reason to develop this project by this paper is because of limited safety knowledge, lack of safety awareness and traditional education method does not supply sufficient safety knowledge. This shows clearly that the advancing in Artificial Intelligence (AI) will help a lot to those who seek for knowledge in different way. Education in AI will give a huge impact to society with better understanding [11].

\subsection{Virtual Reality as educational tools in classroom}

Immersive VR is attracting student in every aspect to learn. Student might lost for certain topic in class, so by using Virtual Reality as a tools in classroom will help a lot the student understanding. Experiment done to investigate science learning by the student. Minecraft plant design demonstrate understanding the respiration and photosynthesis of plant. Student were asked to research the structure and function of the part of the plants and explain these through video presentation or real-time guided tour. From the research found that student much more to attract to the immersived situation. Student will engage a good and better understanding about topic taught [12].

Technology deployment in educational settings is vital if research findings are to have enhance credibility and be translated into practice. Participatory approaches to research are a potent means of exploring the complexity and constraints of embedding technologies, particularly in context of lowincome school communities like in rural area.

Accuracy is crucial when involving in data collection or prediction certain application. High accuracy and high precision gives advantage to user to predict for next planning. Such as in forensic team, they need to determine the age of some specimen by doing some experiment. Thus, Virtual Reality can train someone to master in certain works and be able to reduce technical errors.

Forensic team that require accurate reading such as written documentation of statement as well as photographic documentation of evidence. Plus, by develop this project will help forensic student for medical examination. The injury level is depending on the resolution. More accuracy of data if high resolution of the images gain but vice versa to the low resolution. By any words, this development will help forensic student to gain accurate data of injury happen to certain cases. But depending on the resolution of 3D images.

\subsection{Risk Prevention with Virtual Reality visualization}

Nowadays, many things might be done with Artificial Intelligence such as smart car, smart traffic light, smart building and even smart town in the future. Smart car recently striking in the behavior of the car where the user can communicate with the car. But apparently, smart car might be missing some of important things like accident prevention and accident analysis. Developing risk prevention for a certain cases will help user to avoid accident from occur. Virtual Reality allows for the possibility of encountering dangerous driving condition without putting driver at physical risk [13].

Road construction, hazard or obstacle that giving in the VR will trigger the participant to overcome it safely. From this project development, the user will follow the instruction and user will able to avoid dangers during drive. This teach user from aspect of driving and overcome from dangerous situation include car collision.

\subsection{Existing of Virtual Reality on Raspberry Pi}

Be Your Hero project is one of the existing Virtual Reality games that use Raspberry Pi as a tool in controlling the character in the games. This project is giving user to full gesture control of any virtual hero with set of device using sensors. All the data collected are wirelessly sent to a computer and will display favorite hero on a screen [14].

After user choose the hero, user can control the hero movement like walking or hand gesture by using the set of Raspberry Pi device. This project encourage user to fully control their hero and to complete the task given in the game. 


\subsection{Instructional Design Model}

An Instructional Design model is crucial in providing guideline to make this project development. In other words, Instructional Design model describe the way of how to conduct the various step. Instructional Design is the practice of creating instructional experiences to help facilitate learning most effectively. Instructional Models are also as a guideline or sets of strategies in developing project. Effective instructional models are based on learning theories. Learning Theories describe the ways that theorists believe people learn new ideas and concepts. The field of instructional design includes a wide variety of models from which to choose that guide the instructional design and development process.

\subsubsection{Prototyping Model}

The Prototyping model (Evolutionary) consisted of requirement gathering, quick design, build prototype, customer evaluation, refining prototype and engineer product or product ready. It is dynamic and flexible guideline for building effective training and performance support tools. This model attempt to save time and cost [15].

The instructional goals objectives are established and the learning environment plus with learner's existing knowledge and skills are identified. Some sort of question may be identified here as to get the better requirement.

The quick design phase deals with learning objectives, assessment instruments, exercises, content, subject matter analysis, lesson planning and media selection. The design phase should be systematic and specific. Systematic means a logical, orderly method of identifying, developing and evaluating a set of planned strategies targeted for attaining the project's goals. Specific means each element of the instructional design plan needs to be executed with attention to details.

The building prototype phase is where the developers create and assemble the content assets that were created in the design phase. Programmers work to develop and/or integrate technologies. Testers perform debugging procedures. The project is reviewed and revised according to any feedback given.

During the customer evaluation phase, a questionnaire with several respondent takes place. The user satisfaction or effectiveness in understanding the topic after uses the VR application. Noting its strength and weakness, what needs to be added and should be removed. The developer collects and analyses the remarks from the user.

The refining prototype phase is where the new features is added or removed based on user comments. Second prototype of the new system also constructed. The preceding steps are iterated as many items as necessary until users are satisfied that the prototype represents the final product desired.

Engineer product phase is where the final system constructed. The final system is thoroughly evaluated and tested. Routine maintenance is carried on a continuing basis to prevent large scale failures.

\subsubsection{Waterfall Model}

The Waterfall model was the earliest Process Model to be acquainted. The framework types of Waterfall model are linear-sequential life cycle model. It is easy to use and understand. Waterfall model consists of various phases. In order to ensure there is no overlapping in the phases, each phase needs to be completed before the next phases can start [15].

Waterfall model has six phases. The first phase is requirement gathering and analysis. This phase gathered all the information about the system requirement being developed and make a specific requirement documentation.

The second phase is system design. This phase study the specific requirement from the previous phase and prepare for system design. System Design able to particularize hardware, requirements of the system and specifying whole system architecture.

The third phase is implementation. This phase describes the system that will be developed in a small program known as a unit. Then, this unit will be tested for its processes. This testing is known as the Unit Testing and the inputs are given during the system design.

The fourth phase is integration and testing. This phase explains every unit that have been implemented will integrate into a system. In order to detect any defect, the post-integration will be carried out for the whole system.

The fifth phase is deployment of system. This phase explains the system will be tested their functional and non-functionalities. As the system is no defect, the system will be deployed in the customer environment and release it is into the market with or without enhancement of the system. 
The last phase is maintenance. This phase solves the system again after receiving the feedback from customer environment. The system may be improved to update version and release again into the market. In order to make changes in the client environment, the maintenance needs to be done.

The phases illustrate as a waterfall as the flow is always downwards through the entire phases. All the phases are related to each other. The specialties of the waterfall are the next phase will begin only when the previous phases have achieved goals completely to ensure there is no overlapping occur.

\subsubsection{Agile}

Agile model is made up from the compounding of iterative and incremental process models. The Agile Model specifies on the ability to change the process quickly and meet the needs and satisfaction of the customer in developing the software product. The Agile model begins to be popular due to its characteristic which is flexible and adaptability. There are several methods of agile which are Rational Unified Process (RUP), Scrum, Extreme Programming (XP), Adaptive Software Development and Feature Driven Development. Below will be described the Agile Principle. There are four principle of Agile model that must be consider to develop the system [7].

The first principle is individuals and interactions. This principle explains the development of agile model is concerned on self-organization and motivation. There is strong communication between colocation and pair programming.

The second principle is working software. This principle describes the documentation usually being used as a communication medium. However, demonstration of the function software is preferred to be the best in the communication medium. The developer will communicate with the customer to understand the customer's requirement.

Table 1. Comparison of Methodologies

\begin{tabular}{|c|c|c|}
\hline Model & Advantage & Disadvantage \\
\hline Prototyping & $\begin{array}{l}\text { - } \text { Reduced Time and cost } \\
\text { - Improved user involvement } \\
\text { - Errors can be detected earlier } \\
\text { - Missing functionality can be } \\
\text { - } \text { identified easily } \\
\text { - Quick implementation }\end{array}$ & $\begin{array}{l}\text { - Insufficient analysis } \\
\text { - User confusion } \\
\text { - Excessive development time }\end{array}$ \\
\hline Waterfall & $\begin{array}{ll}\text { - } & \text { Uses clear structure } \\
\text { - } & \text { Determine the end goal early } \\
\text { - } & \text { Transfer information well }\end{array}$ & $\begin{array}{l}\text { - Make change difficulties } \\
\text { - Delay testing until after } \\
\text { completion }\end{array}$ \\
\hline Agile & $\begin{array}{l}\text { - Visibility } \\
\text { - } \text { Efficiency } \\
\text { - Ability to adapt changes } \\
\text { - } \text { Conility to scales } \\
\text { changing requirements } \\
\text { - The rules applied is minimum and } \\
\text { documentation easily engaged } \\
\text { - Convenient to use for fixed or } \\
\text { changing requirement }\end{array}$ & $\begin{array}{l}\text { - Lack of emphasis on necessary } \\
\text { designing and documentation } \\
\text { - Inconvenient for conducting } \\
\text { complex subordinates }\end{array}$ \\
\hline
\end{tabular}

The third principle is customer collaboration. In order to get the suitable product, the customer will keep in touch with the developer. This is due to various factor that led to the requirement gathered is not completely in the early phase of the project. 
The last principle is responding to change. This principle explains the Agile specialties are rapidly responses to the changes and uninterrupted development. The comparison of choosing the best model is shown in the Table 1. Advantage and disadvantage of three type of model is shown.

\section{Methodology}

This section discuss on topic that consist the step or as a guideline for the project development. The selection of the methodology is important as to ensure the goals of this project is clear and also capable of achieving its objective that required in the beginning of the project. Methodology also referred as a set of procedure in developing several project and also used to perform a research to answer the problem statement. This section is about the selection of methodology to develop the project along with instructional design model and comparison of research methodology. The methodology that used in this project is Prototyping model which consist of requirement gathering phase, quick design phase, building prototype phase, customer evaluation phase, refining prototype phase and engineer product phase. The selection of appropriate methodology would help the process of development works well.

In choosing the methodology of the product, the systematic work drawing on existing knowledge gained from research directing to produce new product in order to improve the matter found. Prototyping is the most flexible model for developing this project. The iteration in the phases model provides better management to complete the project. Plus, prototyping is convenient to use for fix or changing environment.

\subsection{Requirement Gathering}

Requirement gathering is the first phase of the methodology. This part has to be done before proceed to the next phase. It is because, we need to select the suitable title for the purpose project. Finding the idea of the project of what to do and how to do it. How to get the user attention by develop the Virtual Reality. This part is very crucial as it needs to identify the requirement from the people. There are three main activities in this phase. The first activity is gathering the requirement. There are several techniques have been used to gather the requirement which are questionnaire, interview and review existing document.

During the questionnaire session, all the information is collected and critical information will be discussed in order to get the requirement from the people. At the same time, an interview technique has been carried out in order to gain the current result. The important documents that related with the business also have been reviewed. After the questionnaire, interview and review document have been made, the second activity which is analyse the requirement is carried out. All the requirements will be analysed. This activity is important to analyse the attribute of the system which is the actor will be used this system and functional involve in this system. The deliverables of this phase are data gathering from questionnaire, Use Case Diagram, Use Case Description, Activity Diagram, Domain Class Diagram, and Sequence Diagram.

After gathering the requirement has been done, the last activity is documented all the requirement into the system requirement document. The deliverable of this phase is Software Requirement Specification (SRS). This SRS is explained further about the software system that are will be established. This SRS will be described the functionality requirement and the list of the use case of the system.

\subsection{Quick Design}

Quick design is the second phase of methodology. There are four activities involved in this phase which are design application environment, design application architecture and software, design user interface, and lastly document the application design.

The first activity in this phase is design the environment. The deliverable is the system environment. Next, design application architecture and software. The deliverables design model which are deployment diagram, component diagram, Design Class Diagram (DCD), Package Diagram and Multilayer Sequence Diagram. DCD will be produced based on domain class diagram. After DCD is done produced, it will be explained in details in class diagram. After that, Multilayer Sequence Diagram will be produced. In the Multilayer Sequence Diagram, it shows the flow of requirement in three-layer design which are the view layer, domain layer and data access layer.

Lastly, Package Diagram will be developed. These diagrams will be created using Microsoft Project. The user interface is system interface that directly involves a system user. The interface is medium to interact between user and system. It is important because it defines the functionality of the interface. 
The deliverable in this activity is user interface which is storyboard. The deliverable is ERD. Then, every diagram that is created in this phase will be documented. The deliverable is the Software Design Documentation (SDD).

\subsection{Building Prototype}

Building prototype phase is the third phase in prototyping model phase. The building phase is developing the system with a source code and including all the requirement that is stated in the SDD and SRS. This application should develop exactly what has been documented and requested by the people. In order to develop this system, Unity 3D software and Microsoft Visual Studio Code software will be used.

The application that will be build must match all the requirement that have already documented earlier to avoid untallied between document and application. The fully functional application with the deliverable in this phase. After completing the task, the third objective will be achieved which is to develop this application.

\subsection{Customer Evaluation}

This phases is the user satisfaction phase. The questionnaire with several respondent are given a chance to try and use the VR application. The respondent are asked about the understanding of the education material inside the application. Respondent also been asked about the attraction in learning by using VR as tools in education. Any changes include the addition features of component or remove some function is based on user feedbacks.

\subsection{Refining Prototype}

Refining prototype phase is where the additional features and many more happens. The new changes are created under new prototype. Some of the negative comment by user is needed to be removed or redesign that suite with the user expectation.

The iteration process takes places until the application is fully satisfied by user evaluation. The iteration happens from phases quick design, building prototype, and customer evaluation. This phase is to ensure that the user is fully engage with the objective of the project.

\subsection{Engineer Product}

This is the final phase in the prototyping methodology phases. The engineer product is also called product ready which means ready to implement. Once the requirement are completely met, the user accepts the final prototype, The final system is evaluated thoroughly followed by routine maintenance on regular basis of preventing large scale failure and minimizing downtime.

\subsection{Hardware and Software}

All developments are carried out using hardware an Intel Core(TM) i5-8300H CPU @2.30GHz, 12 GB

RAM, and 1 TB ROM. The other hardware are smart phone (Android) and Virtual Reality Gears. While the software being used are Unity, Autodesk Inventor Professional 2019, and Visual Studio Code.

\section{Development}

This section discusses on the findings or the research. It is divided into three phases which are requirements gathering and analysis, design and development. Each phase will describe and analyse the deliverables of the project as well the objectives that is achieved through those deliverables.

\subsection{Requirement Gathering}

Requirement gathering is the initial phase of the chosen methodology where information will be collected required to the project title. Researcher using questionnaire and interview techniques from user target in order to gain the content of the application. The interview was carried out among students from Software Engineering and Information Technology courses in Sultan Idris Educational University (UPSI) who ever learn Raspberry Pi.

Regarding to the interview session, interviewee want this application to be displayed in 2D and combining with $3 \mathrm{D}$ mode. Interviewee wants the coding phase to be in $2 \mathrm{D}$ mode while the in-game mode is in VR. For Virtual Reality, the interviewee wants this application to have a learning style which explain to user on Raspberry Pi functionality and user able to integrate with the object while playing. 
Interviewee also suggest that it should be a test game phase where user able to play the game in third person view in controlling the car.

From this phase also, developer had idea of using tools and software required to develop this application which are develop by using Unity 3D, Autodesk Inventor Professional 2019 and Microsoft Visual Studio Code. Developer design the interface of application from Unity itself with canvas and button provided. Other than that, developer also follows Evolutionary Prototyping methodology in developing VR-Pi.

\subsection{Quick Design}

To design and develop of the VR-Pi application, developer will need to use Unity 3D as the framework, Visual Studio Code for programming using C\#, and Autodesk Inventor Professional 2019 to create 3D object. Developer applied the information that gained in previous phase to make sure it is satisfied the requirement needed.

\subsection{Build Prototype}

Build prototype is important in order to proceed with actual development of application. In this stage, developer will design a hands-on coding by using Visual Studio Code while the 3D object will be design by using Autodesk Inventor Professional 2019. In addition, designing interfaces of the application will be using Unity 3D. Through this phase, prototype will follow the entire requirement needed from first phase and follow the methodology. If there are errors and defects in this application, it will be fixed immediately in this phase.

To design the interface in Unity, first, developer create a canvas and insert an image. In this process, developer add other images and make it transition as to make it nicer. Developer also insert the logo off VR-Pi which can be created with free logo maker online. At this stage, the button is created and put as 'child' under the canvas. Developer use Text Mesh Pro as to make the text much clearer. Text Mesh Pro can be installed from asset store which is on top of screen. All the button is set with coding for it able to pressed and change to another scene. As to maintain this main interface in 2D mode, code is put inside of NoVR file.

To design VR interface, developer create the plane and put all the 3D object at the top of panel. The mushroom asset can be installed from asset store. The developer also used Sky Box which can be installed from asset store. Developer create video player from Powtoon and insert into video player file. On the right screen shows how to set the video into the screen. At this stage, VR mode coding is put into VRMode file.

Configure is the most crucial stage. Developer configure all the build in setting in the Player Setting. In XR settings, developer enable the Virtual Reality Support and insert with none follow by Cardboard. This is important as to make the system read none first before Cardboard. Inside none, developer create a coding which is 2D mode. While Cardboard is Google Cardboard SDK which is 3D mode.

\subsection{Evaluate with User}

In this phase, researcher give target users that include Software Engineering students from Sultan Idris Education University and lecturer to try the application in order to satisfy requirement needed. After they already used it, researcher gives questionnaire to students to justify their understanding about VRPi.

Researcher also run interview session with lecturer who is interested in Virtual Reality things and ask whether this application need to add some functions. Regarding to the questionnaire and interview session, there are some functions that need to add so that VR-Pi gives more understanding to user about the learning and gives more attractive while students used VR-Pi in this application. All the requirements gathered will be discussed in next phase.

\subsection{Refine Prototype}

After gives questionnaire to students and interview session carried out with lecturer, the requirements of the application need to improve and add some functions. Developer create a 3D building and combine with door as to make the scene much more attractive. This door also functions as to change to another scene. 


\subsection{Quick Design}

Another adjustment has been made as to fulfil user expectation. User want a building with door and able to change to another scene. Developer design the 3D building by using Autodesk Inventor Professional 2019. On the top side of screen is the tools that can be use. Most of the time developer only use extrude and fillet. On the left side of screen is the parent and child of the project. After finish designing the building, developer save as obj file and drag the file into Unity3D project file. In the Unity need to adjust the scale as to make it much better.

\subsection{Build Prototype}

On this stage, the final product of designing the environment is done as to fulfil the user expectation. Developer apply the material on the building and create 3D text on top of building. Developer also design the area with mushroom and other trees around the building as to make it more attractive.

\subsection{Evaluate with User}

In this phase, developer gives back to the students and lecturer from previous evaluation to try this application prototype. After they already used it, researcher will ask whether the application need to be added for another feature. Regarding to the question, students and lecturer satisfied with the current functions provided in VR-Pi prototype.

\subsection{Engineer Product}

On this stage, after all the feedback from the user been resolve. The final product of VR-Pi with the version 1.0 is ready.

\subsection{Software Used}

This is the overall of software used by developer in order to develop VR-Pi.

\subsubsection{Unity}

Unity is a complete open-source for mobile app development. Unity is a cross-platform game engine developed by Unity Technologies, first announced and released in June 2005 at Apple Inc.'s Worldwide Developers Conference as a Mac OS X-exclusive game engine. Unity3D is a powerful cross-platform 3D engine and a user friendly development environment. Easy enough for the beginner and powerful enough for the expert. Unity should interest anybody who wants to easily create 3D games and applications for mobile, desktop, web, and consoles.

\subsubsection{Autodesk Inventor Professional 2019}

Autodesk Inventor software provides engineers and designers a professional grade solution for 3D mechanical design, simulation, visualization, and documentation. Autodesk Inventor includes powerful modelling tools as well as multi-CAD translation capabilities and industry standard DWG drawings.

\subsubsection{Visual Studio Code}

Visual Studio Code is the powerful software that used for write the coding for developing the application. The language that are being used is Angular, TypeScript, JavaScript, HTML, CSS, and Firebase. For Angular, HTML and CSS, coding for the front-end of the application. While for back-end use TypeScript, JavaScript and Firebase.

\section{Results and Finding}

After design and development phase, developer will proceed to evaluation phase. This chapter will discuss about usability evaluation of VR-Pi application. Developer will evaluate the application with 19 respondents that have curiosity in learning IoT. Based on the findings, there is the data that have been collected.

Based on the Figure 1, the result of the gender show that 60 percent of male participant this questionnaire compared to 40 percent of female. While in Figure 2, the result of the department show that 63 percent of respondent is from FSKIK department, while 11 percent on FSMT, 16 percent from FSSKJ, FBK and FPM is sharing with 5 percent each. 


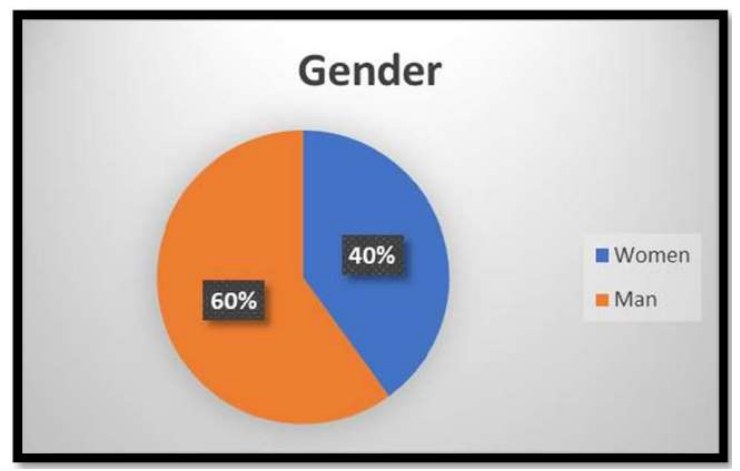

Figure 1. Result for Gender

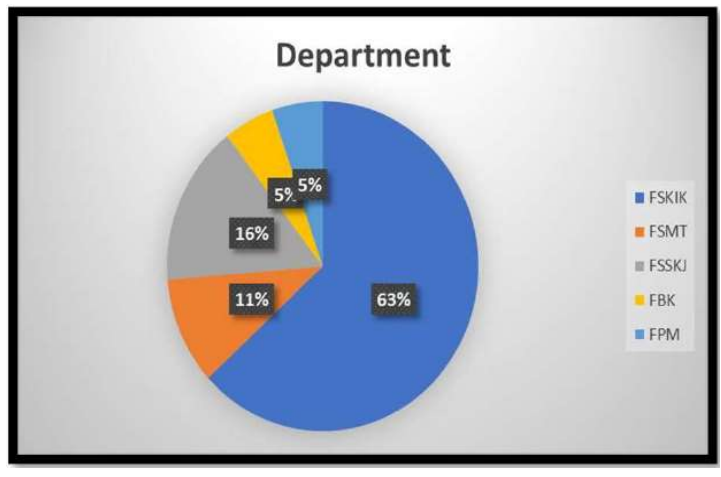

Figure 2. Result for Department

\subsection{Results of finding for four aspects}

Based on the findings, there is the data that have been collected. This using scalar values that is 1 to 7 . For 1 is strongly disagree, 2 less disagree, 3 disagree, 4 neutral, 5 less agree, 6 agree, and 7 is strongly agree.

\subsubsection{Usefulness}

Based on Figure 3, the result of the first question of the usefulness, the bar chart show that 54.5 percent agree and 27.3 percent strongly agrees that VR application may help student to gain more information about Raspberry Pi. Only 18.2 percent choose less agree.

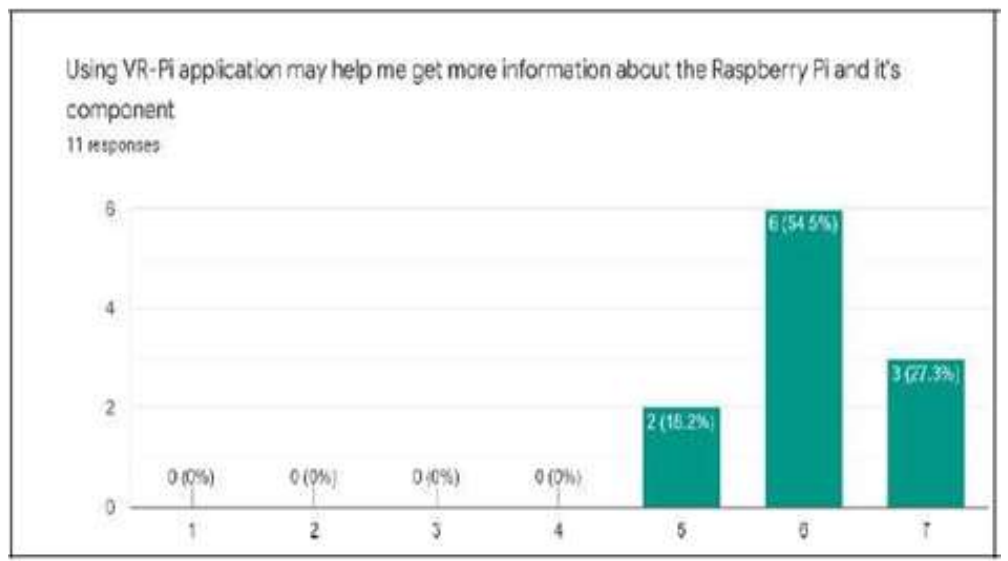

Figure 3. First Aspect of Usefulness 
Figure 4 shows that 63.6 percent strongly agrees and 27.3 percent agree that VR-Pi application may compatible with technologies that are while only 9.1 percent are less agree.

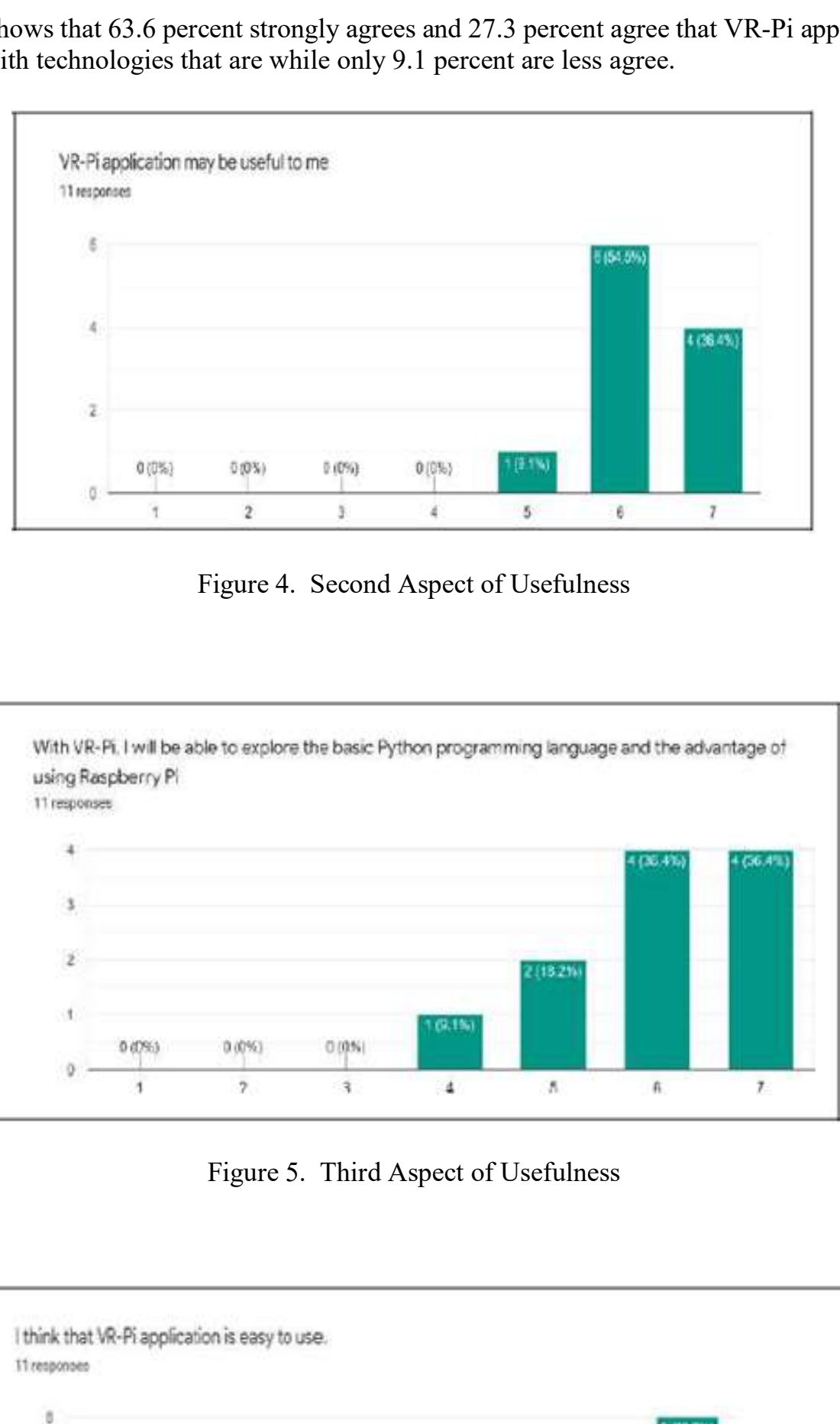

Figure 4. Second Aspect of Usefulness

With VR-FI. I will be able to explore the basic fython programming language and the advantage of using Raspberry PI

11 respenset

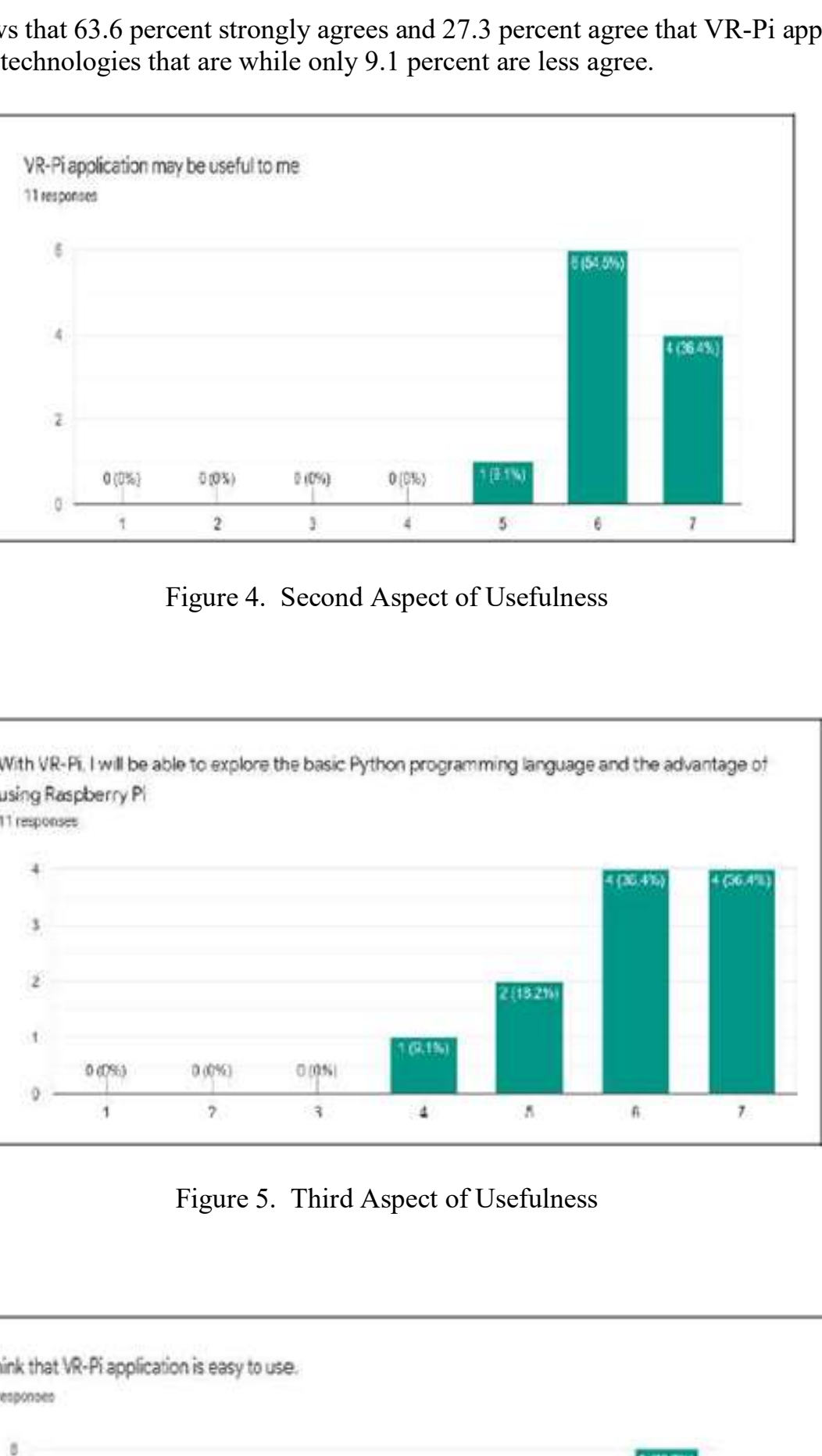

Figure 5. Third Aspect of Usefulness

Ithirk that VR-Pi appication is easy to use.

t1 responses

उल2खा

8

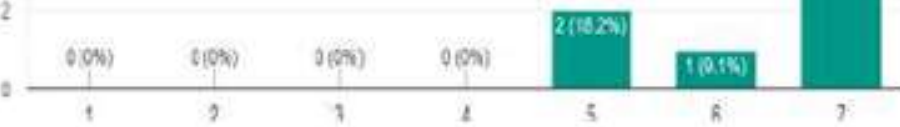

Figure 6. Fourth Aspect of Usefulness 
Figure 5 shows 36.4 percent strongly agrees and 54.5 percent agrees that VR-Pi application may be useful to me. Only 9.1 percent are less agreeing on this question. Figure 6 shows 36.4 percent strongly agrees and agree that with VR-Pi, they will be able to explore the basic Python programming language and the advantage of using Raspberry Pi. 18.2 percent are less agreed and 9.1 percent are neutral on this question.

\subsubsection{Ease of Use}

Based on Figure 7, the result of the second question of the ease of use, the bar chart show that 72.7 percent strongly agree and 9.1 percent agrees that VR-Pi application is easy to use. Only 18.2 percent choose less agree. Next in Figure 8, it shows that 27.3 percent strongly agrees and 36.4 percent agrees that I think that instruction provided are clear and details to use VR-Pi application. While only 27.3 percent are less agreed and 9.1 percent are neutral.

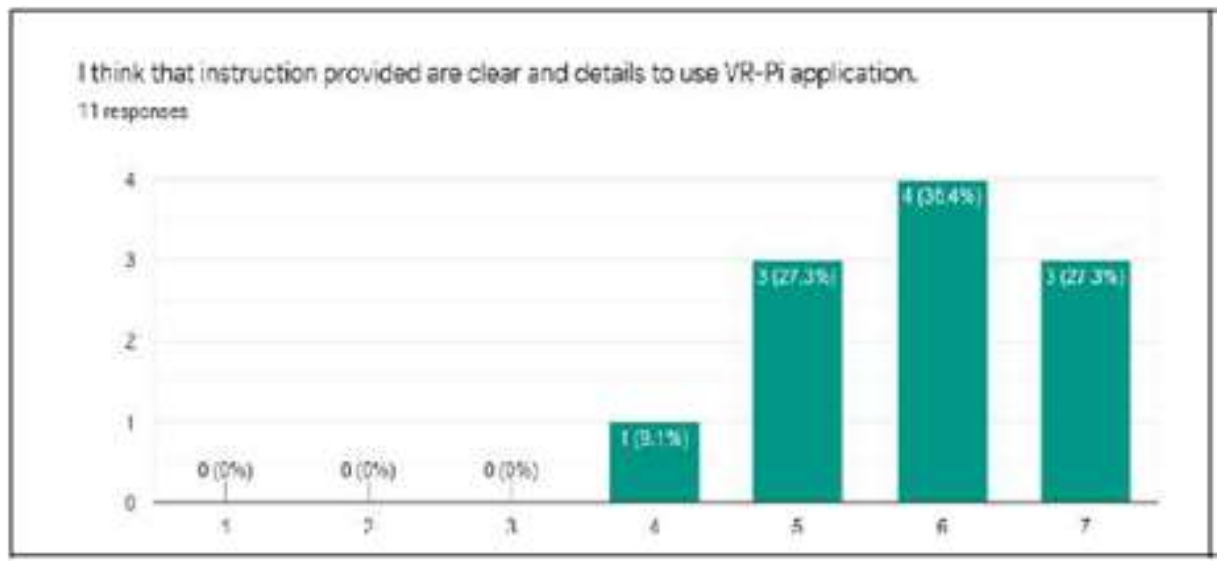

Figure 7. First aspect of Ease of Use

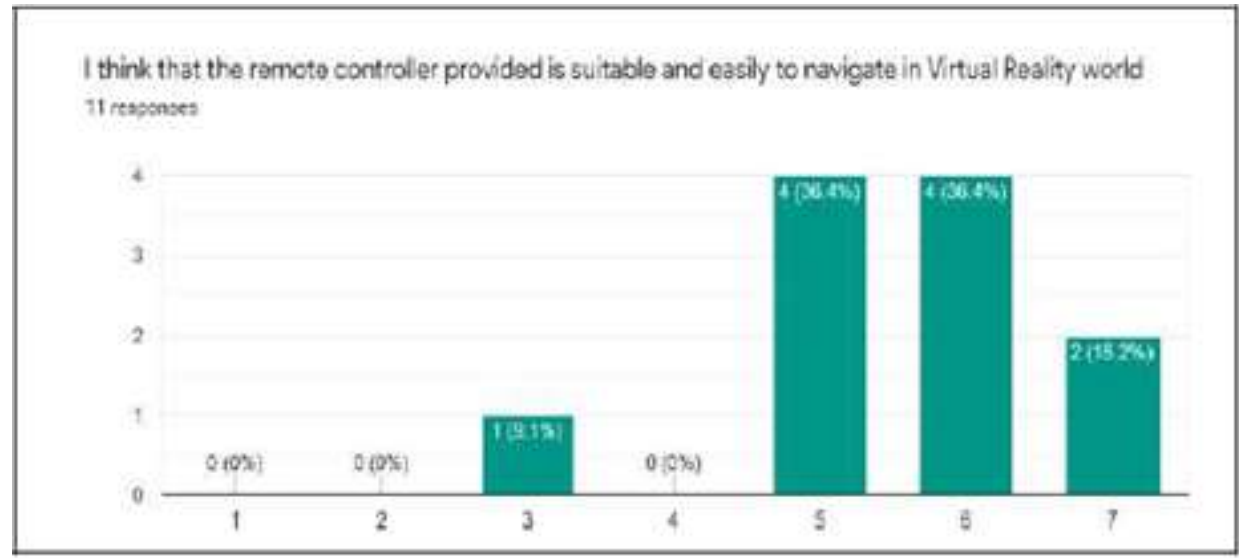

Figure 8. Second aspect of Ease of Use

\subsubsection{Ease of Learning}

The result of the third question of the ease of learning, the bar chart show that 27.3 percent strongly agree and 18.2 percent agrees that I think that the VR-Pi application is suitable for learning in building things by using Raspberry Pi. Only 54.5 percent choose less agree. 


\subsection{Percentage Score}

The percentage score for 'I think that the note provided is appropriate and easy to understand' question has gain the highest score was 86 percent. While the lowest score of 'I think that the remote controller provided is suitable and easily to navigate in Virtual Reality World' question was 72 percent.

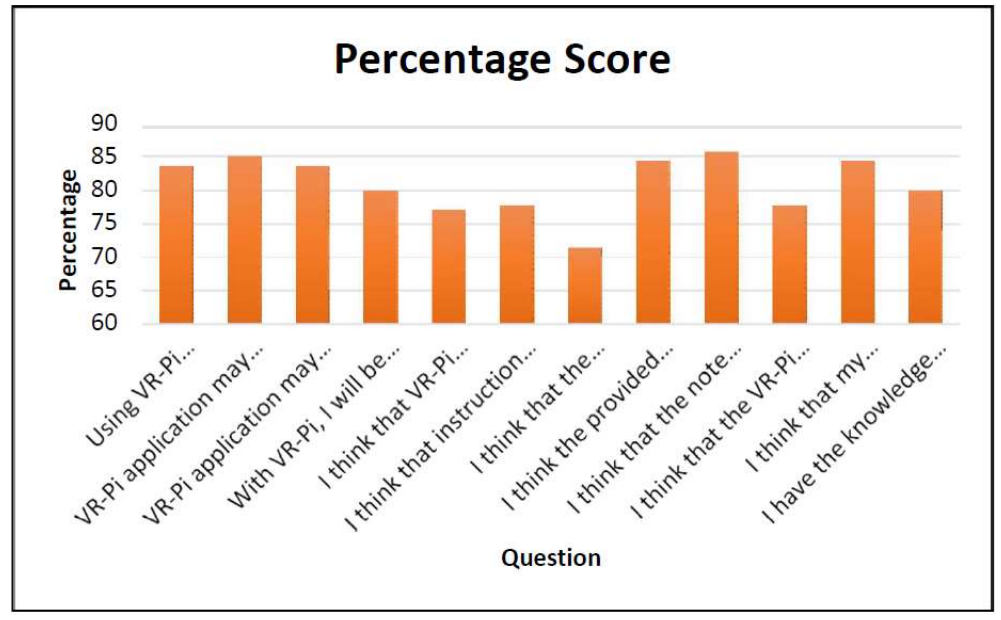

Figure 9. Results for Questionnaire Score

\section{Conclusion}

As the system for the project has been completed, the objectives of the project have been achieved. With the objectives have been achieved, the significance of this project can extend in the future, to the researcher who are interested in continuing this system. There are several suggestions for this system that can be done:

1. Set a pipeline for user to move instead of free move from controller.

2. Use a much better VR gear such as Oculus Rift for better interaction between user and system.

3. Create a $3 \mathrm{D}$ character that explain how to configure on certain things on much detailed.

All of the recommendations are recommended as it can enhance the systems to be more efficient and can help with the productivity in the industry.

\section{References}

[1] Lexico. (n.d.). Virtual Reality: "Meaning of Virtual Reality," 2017. [Online]. Available: https://www. lexico.com/definition/virtual_reality. [Accessed on: March 21, 2019.]

[2] M. Malik, "Amanat Menteri Pendidikan Tinggi 2018, Tema - Pendidikan Tinggi 4.0: Ilmu, Industri dan Insan," 2018.

[3] E. Southgate, S. P. Smith, C. Cividino, S. Saxby, J. Kilham, G. Eather, and C. Bergin, "Embedding immersive virtual reality in classrooms, ethical, organisational and educational lessons in bridging research and practice," International Journal of Child-Computer Interaction, vol. 19, pp. 19-29, 2019. doi: 10.1016/j.ijcci.2018.10.002.

[4] S. Ferdoush, and X. Li, "Wireless Sensor Network System Design Using Raspberry Pi and Arduino for Environmental Monitoring Applications," Procedia Computer Science, vol. 34, pp. 103-110, 2014. doi: 10.1016/j.procs.2014.07.059.

[5] Y. Pulijala, M. Ma, M. Pears, D. Peebles, and A. Ayoub, "An innovative virtual reality training tool for orthognathic surgery," International Journal of Oral and Maxillofacial Surgery, vol. 47, no. 9, pp. 1199-1205, 2018. doi: 10.1016/j.ijom.2018.01.005.

[6] S. Faroque, M. Mortimer, M. Pangestu, M. Seyedmahmoudian, and B. Horan, "Evaluation of a new virtual reality micro-robotic cell injection training system," Computers \& Electrical Engineering, vol. 67, pp. 656-671, 2018. doi: 10.1016/j.compeleceng.2017.04.030.

[7] M. Jia, A. Komeily, Y. Wang, and R. S. Srinivasan, "Adopting Internet of Things for the 
development of smart buildings: A review of enabling technologies and applications," Automation in Construction, vol. 101, pp. 111-126, 2019. doi: 10.1016/j.autcon.2019.01.023.

[8] D. Sportillo, A.Paljic, and L. Ojeda, "Get ready for automated driving using Virtual Reality," Accident Analysis \& Prevention, vol.118, pp.102-113, 2018. doi: 10.1016/j.aap.2018.06.003.

[9] S. Koller, L. C. Ebert, R. M. Martinez, and T. Sieberth, "Using virtual reality for forensic examinations of injuries," Forensic Science International, vol. 295, pp. 30-35, 2019. doi: 2018.11.006.10.1016/j.forsciint.

[10] C. J. Mccarthy, and R. N. Uppot, "Advances in Virtual and Augmented Reality-Exploring the Role in Health-care Education," Journal of Radiology Nursing, vol. 38, no. 2, pp. 104-105, 2019. doi: 10.1016/j.jradnu.2019.01.008.

[11] Y. Jia, and A. G. Campbell, "Immersive Virtual Reality Training Tool for IoT Device Placement," Proceedings of the 10th EAI International Conference on Simulation Tools and Techniques - SIMUTOOLS 17, 2017. doi: 10.1145/3173519.3173521.

[12] M. Domb, "Smart Home Systems Based on Internet of Things," IoT and Smart Home Automation, 2019. doi: 10.5772/intechopen.84894.

[13] J.Huuskonen, and T. Oksanen, "Soil sampling with drones and augmented reality in precision agriculture," Computers and Electronics in Agriculture, vol. 154, pp. 25-35, 2018. doi: 10.1016/j.compag.2018.08.039.

[14] D. E. Qeshmy, J. Makdisi, E. Hans, D. Ribeiro, J. Da Silva, and Angelis, "Managing Human Errors: Augmented Reality systems as a tool in the quality journey," Procedia Manufacturing, vol. 28, pp. 24-30, 2019. doi: 10.1016/j.promfg.2018.12.005.

[15] G. Quero, A. Lapergola, L. Soler, M. Shabaz, A. Hostettler, T. Collins, and P. Pessaux, "Virtual and Augmented Reality in Oncologic Liver Surgery," Surgical Oncology Clinics of North America, vol. 28, no. 2, pp. 31-44, 2019. doi: 10.1016/j.soc.2018.08.002. 